\title{
ANALYSIS OF GROUND TRANSPORT SECURITY OF EMERGENCY MEDICAL SERVICES IN DEAL WITH EXTRAORDINARY EVENTS
}

\author{
Miroslav TOMEK ${ }^{1}$, L’uboslava LAŠOVÁ
}

Review article

\begin{tabular}{ll}
\hline Abstract: & Article presents an analysis of the transport security ground emergency medical services \\
& (hereinafter GEMS) Slovak Republic (hereinafter SR) in dealing with extraodinary \\
& events (hereinafter EE). The first part deals with the laws of ambulances GEMS. The \\
& following sections analyze the development of primary and secondary interventions and \\
& interventions in road accidents. The last part is the draft of the transport security of EE \\
& by ambulances of GEMS. \\
Keywords: & Ambulance, Extraordinary events, Health, Security, Transport.
\end{tabular}

\section{Introduction}

Every EE solution allows in terms of traffic ensuring involves the use of the necessary forces and resources in the right place, at a particular time, in the required amount in the required quality and at a reasonable cost. If in the area of EE are present victims (injured and disabled persons) is the need to deploy and properly coordinated, inter alia, sufficient forces and means of GEMS. Often EE are road accidents.

Activities and successful operation of GEMS requires legal, organizational, material and technical, personnel, and of course financial security. Requirements for material and technical equipment and personnel of GEMS are directly defined in the relevant legislation.

\section{Materials and methods}

Providing emergency medical care is governed by different laws. Already in Constitution of the SR in Article 40 is enshrined as one of the fundamental human rights, the right to health. Due to the need to regulate the rescue, particularly the organization and coordination in dealing with different EE, was adopted the law no. 129/2002 about integrated rescue system in 2002 by National Council (hereafter NC) of SR (Lašová, Tomek, 2009).

Several laws dealing with GEMS were approved in 2004 and to this time have been amended several times. Currently, all emergency medical service (hereinafter EMS) is bound by following applicable laws:

- Act of the National Council no. 579/2004 of the emergency medical service and on amendments to certain laws, which defines the EMS provides emergency health care in the intervention area, which is the whole territory of the Slovak Republic. It includes organization of EMS, obligations of Operation Centre EMS and EMS providers;

- Act of the National Council no. 578/2004 of healthcare providers medical professionals, and professional organizations in the health and amending certain laws, which, in its second part discusses the conditions of operation of EMS;

- Act of the National Council no. 577/2004 of about the range of health care covered by public insurance, and payments for services related to the provision of health care;

- Act of the National Council no. 576/2004 of health care services related to health care and on amendments to certain laws;

- Decree of the Ministry of Health (hereinafter MH) SR of 11 March 2009 no. 10548/2009-OL laying down the details of the emergency medical service as the Ministry of Health Decree no. 14016/2010OL of 9 July 2010, which among other things deals with material, technical and staffing OC EMS, stations GEMS and Helicopter emergency medical services (HEMS) and ambulances;

- Ministry of Health Decree of 23 March 2010 no. 11378/2010-OL, which provided office stations of GEMS and HEMS (Lašová, 2010).

Rescue groups GEMS are made of health workers and provide medical assistance in direct contact with the injured. Necessity is their competence to practice, which is governed by:

- Decree of the Ministry of Health of the Slovak Republic no. 366/2005 of the criteria and the way the continuing education of health professionals;

\footnotetext{
University of Žilina, Faculty of Special Engineering, Žilina, Slovak Republic, miroslav.tomek@fsi.uniza.sk

2 Kysucké Nové Mesto, Slovak Republic, luboslava.lasova@gmail.com
} 
- Decree of the Ministry of Health of the Slovak Republic no. 321/2005 of the scope of practice in some health professions, as amended, which governs the scope of practice of a doctor and a paramedic in EMS;

- Government Regulation no. 296/2010 of competency to perform the medical profession, how to further education of health professionals, system training courses and certified system of work activities.

GEMS ambulance stations and ambulances went from 1992 to the present time significant changes, mainly in the number of stations and their modernization. The most important period of the time can be considered 2004, in which the reform was adopted to ensure the availability of time to provide emergency medical care within 15 minutes. As a result of the reform was the increased number of stations from the original 94 to the 259. Overview of GEMS stations since 1992 with an average population per ambulance is shown in Tab. 1 .

Tab. 1 Summary of ground stations, emergency medical services and population changes (Lašová, 2010)

\begin{tabular}{|c|c|c|c|}
\hline Year* & $\begin{array}{c}\text { Number } \\
\text { of stations } \\
\text { GEMS }\end{array}$ & $\begin{array}{c}\text { Number of } \\
\text { inhabitants in } \\
\text { Slovakia }\end{array}$ & $\begin{array}{c}\text { Average } \\
\text { population/1 } \\
\text { GEMS }\end{array}$ \\
\hline 1992 & 72 & 5306539 & 73702 \\
\hline 1993 & 94 & 5324632 & 56645 \\
\hline 2004 & 259 & 5384822 & 20790 \\
\hline 2008 & 264 & 5424925 & 20549 \\
\hline 2010 & 273 & 5426645 & 19878 \\
\hline
\end{tabular}

* year of implemented changes.

GEMS activity stations are coordinated by the Regional Operation Centre (hereafter ROC) of EMS. According to the state of a person's life in danger, or the number of injured and disabled, because of the need to provide emergency medical care gives ROC EMS command to one or more ambulance with a doctor or with no doctor.

From a medical point of view, to take up the activities necessary for life saving injured people a very important is the time of arrival of professional medical assistance (Buliková, 2011). The legislation of SR does not set time roll ambulance to EE place instead of receiving the order to exit. In the countries of the European Union (EU) is usually customary time of 15 minutes and some countries have this time embodied in laws or ordinances.
The largest autonomous region in Slovakia is Bánska Bystrica region with number of 46 stations of GEMS. It is also the region, where 15-minute range of ambulance is cecured only to 441 villages from total amount of 516 villages, what is $75 \%$ of villages. According to calculations (taking into account the category of road and achieved an average speed of ambulances) is best secured region Žilina region. Theoretical time to roll out the ambulance stations GEMS, established in Žilina region to all 315 municipalities is fifteen minutes. Providing emergency medical care is provided in Žilina region through 36 ambulances.

The Fig. 1 shows the development of primary interventions in proportion to the population for the period 2007 - 2011 in the autonomous regions of Slovakia. The statistics of operation centre (hereinafter OC) EMS shows that in 2011 has been carried out along 445235 primary interventions, representing over 2010 by $0.5 \%$ less than in 2009 and it is about $3.38 \%$ more.

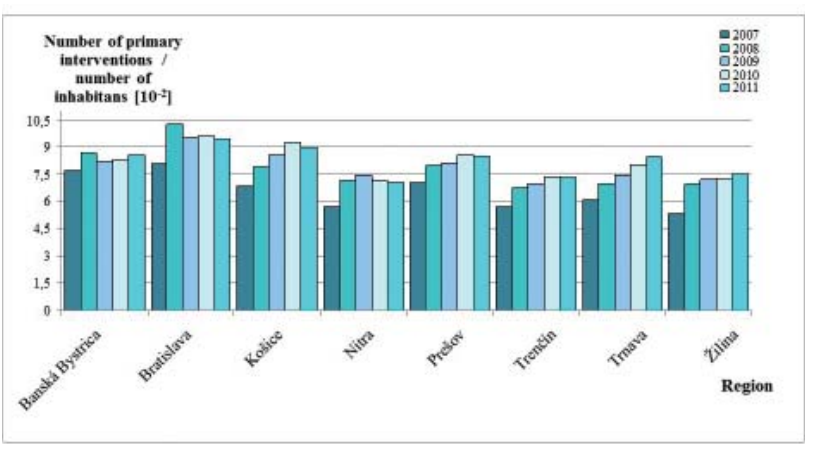

Fig. 1 Development of primary interventions ground emergency medical services between 2007 and 2011 (Lašová, 2012)

Currently is the territory of SR covered by 273 GEMS stations where an average of one ambulance provides emergency health care to 19878 inhabitants. Recent changes in settlements of GEMS stations in Slovakia (implemented in 2010) provide the theoretical range of ambulances within 15 minutes from the exit of the ambulance from GEMS station up to $93.204 \%$, which represents 2726 municipalities in Slovakia (Lašová, 2012).

Most interventions in proportion to its population in the last year, 2011, were conducted in the Bratislava region, at least in Nitra. The year 2011 saw an increase in the number of primary interventions compared to 2010 in Banská Bystrica, Prešov, Trenčín and Žilina Region.

According to data from the OC EMS mean the time roll of ambulances in 2011 by the performance of the primary intervention increased from 
10.4 minutes in 2010 to 11.3 minutes. Ambulances of emergency medical assistance achieved averaged 10.4 minutes (12\% increase) and ambulances of emergency medical help 11.9 minutes (6\% increase). GEMS busiest station in the SR station with emergency medical help was in Michalovce operated by Zachranna sluzba Košice. Provider performed a total of 3624 primary interventions. Realized in average of 10 trips per day and the average time to roll out its designated location was 11.3 minutes (Lašová, 2012).

The development of secondary interventions is shown in figure number 2. The mean duration of secondary intervention in 2011 increased compared with previous years to 145.6 minutes.

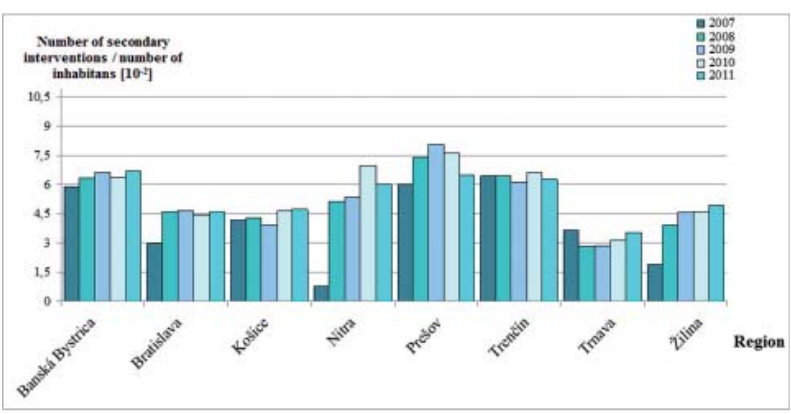

Fig. 2 Development of secondary interventions ground emergency medical services between 2007 and 2011 (Lašová, 2012)

Most secondary interventions were implemented in Prešov region (5 247). Most used emergency medical help in SR was an anbulance with sitting village of Stare Hory. Emergency medical help realized 458 secondary interventions in 2011.

According to the statistical indicators is the total number of outpatient interventions across SR steadily increasing. In 2010 GEMS was mainly used at the time of 7:00 am to 3:00 pm. Mentioned time was used as the time for implementation of primary and secondary interventions. High workload intervention group clinics are reflected in the period from 10:00 pm to 0:00 hours, when it was realized together 34479 primary and 825 secondary interventions.

The main reason for the increasing number of implemented interventions of GEMS is particularly deteriorating health of an aging population of SR.

Ground ambulance service is also used in road accidents (Buliková, 2011). The statistical overviews of traffic accidents in SR processed for the years 2007 to 2011 shows decreasing number of accidents. The number of casualties in road accidents, which are dependent on the rapid provision of emergency medical care, also decreases, but at a slow pace compared to accidents, shown in Tab. 2.

Tab. 2 Overview of traffic accidents between 2007 and 2011 (Lašová, 2012; Statistics, 2012)

\begin{tabular}{|c|c|c|c|c|c|}
\multirow{2}{*}{$\begin{array}{c}\text { Development } \\
\text { of traffic } \\
\text { ccidents [\%] }\end{array}$} & \multicolumn{4}{|c|}{ Number of injuries } & Development \\
\cline { 2 - 6 } & dead & $\begin{array}{c}\text { severely } \\
\text { of number of } \\
\text { injured }\end{array}$ & $\begin{array}{c}\text { lightly } \\
\text { injured }\end{array}$ & together [\%] \\
\hline-1.56 & 627 & 2036 & 9274 & 11937 & 5.91 \\
\hline-3.38 & 558 & 1806 & 9234 & 11598 & -2.84 \\
\hline-55.96 & 347 & 1408 & 7126 & 8881 & -23.43 \\
\hline-16.85 & 345 & 1207 & 6943 & 8495 & -4.35 \\
\hline-30.57 & 324 & 1168 & 5889 & 7381 & -13.11 \\
\hline
\end{tabular}

Decrease more than $55 \%$ in traffic accidents in 2009 is recorded, the reason for the measures in the new law adopted by the National Council no. 8/2009 of on Road Traffic and on amendments to certain laws. The decline of the victims in 2009 compared to 2008 was $23 \%$. In 2010, the number of accidents decreased from 2009 by more than $16 \%$ and the number of victims by only $4 \%$. A significant decrease in the number of traffic accidents was in 2011 compared to 2010, when it recorded a decrease to $30.57 \%$ accidents and $13.11 \%$ decrease in casualties.

The formation of an accident affecting traffic flow, weather effects, index of industrial production and other factors. A common cause of accidents is human error, particularly inattention, fatigue and failure as a breach of safety rules and breach set vehicle speed (Štetina, 2000).

\section{Results}

Rescue groups often intervene GEMS in EE, which give rise to a large number of victims in one place. Such events include, in particular bus traffic accidents (2007 in Trenčín, 2009 in the village Polomka etc.), a chain car accidents on the roads in SR.

Special events with large numbers of casualties may occur even in companies that are in the business of working with dangerous substances (for example, 02/03/2007 there was an explosion in the Military Repair business as, Novaky, etc.) or in places where a large number of people (sports and cultural events, check-in hall at airports, railway stations in the cities, schools, etc.). On all these EE's terms of transport need to be addressed with some amenities and emergency preparedness components. It is necessary not only fast in a short time frame to ensure strength and resources of EMS in place of EE, but also to create the conditions to ensure traffic management intervention (the ability to 
provide communication facilities for staff, adequate supply of medicines, medical supplies, devices, appliances, another necessary transport equipment, etc.) (Smetana, Zdráhal, 2011).

Organization of transport security GEMS in the place of EE can be divided into two phases. In the first phase is expected to implement interventions primarily first and second sequence of vehicles GEMS to the place of EE and in the second phase will be conducted secondary transports.

The first phase of organizing transport security begins upon receipt of an emergency call for COS EMS and ends passing last injured patient to the designated medical facility. Terms of time, it may take from 10 minutes to 12 hours. Transportation security GEMS may be affected, in particular:

- feature area of EE (eg, terrain, time of day),

- weather conditions,

- the number of disabled persons,

- mode of transport injured,

- the number of clinics that are available,

- capacity vehicles for the transport of wounded, etc.

The second phase of organizing transport security GEMS at EE includes secondary interventions. Some injuries are in need of assistance that will be provided in specialized medical equipment.

Main activity of GEMS that takes place in the first phase will also roll out fast and safe place for EE provision of urgent medical care. The arrival of an ambulance at the place of EE should be provide first aid to injured by bystanders or participants unscathed. Among the activities that are expected to perform in the first phase particularly in terms of transport include:

- nearest free ambulance will be sent to EE place by ROC,

- ambulance transfer from GEMS station to the place of action,

- continuous communication with the operator ROC EMS with first ambulance intervention group,

- analysis of the situation in the place of EE by first intervention group,

- profession required number of manpower and resources GEMS,

- provide professional medical assistance in a limited space EE,

- transport the injured to medical facilities, etc.

The first sequence is formed by ambulances that will implement the exit of stations as is described by ROC EMS immediately for quick adoption and evaluation of emergency. After receiving specific information (the number of people affected by EE) from the first point of intervention group in EE, ROC EMS gives the command to exit forces and other resources that make up the second sequence. Their choice to send staff to EE place has to be as fast as possible. In case of good weather, can be use HEMS in the prace of EE. Tab. 3 contains a number of customary numbers of ambulances that would be sent KOS EMS operators to deal with him in case of a large number of casualties in one place.

Tab. 3 Number of ambulances in emergencies

\begin{tabular}{|c|c|}
\hline Number of injuries & $\begin{array}{c}\text { Number of ambulances } \\
\text { in emergencies }\end{array}$ \\
\hline $3-10$ & $3-5$ \\
\hline $11-20$ & $5-10$ \\
\hline $21-100$ & $10-15$ \\
\hline nad 100 & $20-25$ \\
\hline
\end{tabular}

In terms of traffic will be the needed to take a maximum attention to the parking area for the necessary transport equipment and particularly ambulance, Fire Fighting vehicles, Police vehicles and special equipment. At the parking area for vehicles will be centered ambulances, which will be used to transport wounded. The unit commander will be responsible for removal by using the appropriate urgency ambulance with the necessary equipment and medical personnel, or other means of transport to organize evacuation affected.

As the first patients to be transported from the places EE will be those with red label priority by TRIAGE. For their transport is expected to use an emergency medical assistance ambulance. Transport moderately injured marked in yellow-red card sorting by priority will be done outpatient type emergency medical assistance, if not already available, will be ued ambulances emergency medical help type. Injuries with yellow label priority may be transported to a medical facility by ambulances of emergency medical help type. For removal of easily injured is expected to also use the emergency medical help type ambulance. If suitable climatic conditions for the rapid transport of seriously injured persons can also use HEMS ambulance. For this reason it will be necessary to set the the helipad.

Evacuation route should be provided with a sufficient number of police officers and should ensure passage of the required number of traffic technique. Location of habitat removal should take into account the simplest smooth arrival and departure of all vehicles. 
Within the EU, the average number of people per ambulance is less than 25000 . Operation of GEMS stations with two or more outpatient ambulances in some European countries has contributed to a reduction in installation costs associated with the construction of stations. Twelve hour operation of some GEMS stations (eg in Poland) in turn provides lower costs for their individual operation.

In the meantime is not used system rendez-vous in Slovak Republic. This system of emergency medical care, although some benefits as a faster arrival physician for a personal vehicle to place of EE and lower number of employed physicians in GEMS, but it also has disadvantages. The main disadvantage is the need of establishing a network of more GEMS stations, which means higher financial costs not only for the establishment, but also the operation of stations.

As mentioned above, the Slovak legislation does not set time roll ambulance to the place where it is necessary to provide urgent medical care, as for example in the Czech Republic (CR) or in Poland. In Germany, each province has its independent act about rescue service where is also strictly determined time standard, such as 12 minutes in Bavaria, Hesse 10 minutes. In London, where the emergency dispatching computer determines that the nearest ambulance arrival at the place of intervention would last more than seven minutes, the paramedic goes to the action by a motorcycle or bike to ensure rapid provision of emergency medical care until the ambulance arrives.

Number of GEMS ambulance stations is connected with time range and their distributions. Of course GEMS distribution channels also depends on the size and population of the area covered by each ambulance.

Ambulance response in SR territory have the entire territory of Slovakia, the Czech Republic is within the scope of their regions in which they are located. The average daily performance of one ambulance in action in SR is 4.7 actions, which is the validity of the use GEMS. In neighboring countries, an average of one such ambulance is performed 3.8 actions in Czech Republic, 3 interventions in Kingdom of Denmark and Sweden and 4 hits a day in UK.

\section{Conclusion}

The overall analysis of the current state of GEMS stations shows observation of the station GEMS be ready 24 hours a day for primary or secondary intervention. According to statistics in the SR primary intervention is carried in average of one in six emergency call of number 155. Exit ambulance to intervene, according to the law no. 579/2004 of must be carried out within one minute of receiving the call from ROC EMS.

In order to manage the provision of emergency medical care to a large number of traffic casualties in terms of security is very important to put in place of $\mathrm{EE}$ the required number of the ambulances with medical personnel as soon as possible. The rapid arrival of ambulances mainly affects the timely availability of EE area. It is therefore necessary that the number of GEMS stations in each autonomous area was reasonable, and must take into account the need for the implementation of secondary interventions. In the performance of secondary interventions rebound to "partially uncovered networks" of GEMS.

\section{Acknowledgments}

This study/publication was developed with the support of the Operational Programme Research and Development for the project: Centre of excellence for systems and services of intelligent transport II., ITMS 26220120050 supported by the Research \& Development Operational Programme funded by the ERDF. 


\section{References}

BULÍKOVÁ, Táňa at al. (2011). Disaster medicine. Martin: Osveta, 2011. 418 s. ISBN 978-80-8063-361-5. (in Slovak).

JANOŠEC, Jozef. (2010). Fire safety in reality (2010). TRANSACTIONS of the VŠB - Technical University of Ostrava, Safety Engineering Series. 2010, No. 1, Vol. V, pp. 35 - 44. ISSN 1801-1764. (in Czech).

LAŠOVÁ, L'uboslava. (2010). Development of ground emergency medical services in the Slovak Republic. In: LOGVD - 2010 Transportation logistics and crisis situations. Zilina: University of Žilina, 2010. pp. 129132. ISBN 978-80-554-0271-0. (in Slovak).

LAŠOVÁ, L'uboslava. (2012). The transportation security of emergency medical services during emergency situation. Written project of dissertation exam. Zilina: Faculty of Special Engineering, University of Žilina Department sciences and informatics. 2012. (in Slovak).

PANÁKOVÁ, Luboslava, TOMEK, Miroslav. (2009). Emergency medical servise in emergencies. In: LOGVD Transportation logistics and crisis situations. Zilina: University of Žilina, 2009. pp. 233-239. ISBN 978-80554-0114-0. (in Slovak).

SMETANA, Marek, ZDRÁHAL, Karel. (2011). Selected problems of terminology used in the context of crisis management within the legal framework of the Czech Republic. Transactions of the VSB - Technical University of Ostrava, Series Safety Engineering. Ostrava, 2011, roč. 6, č. 1, s. 23-26. ISSN 1801-17694. (in Czech).

Statistics on traffic accidents. 2012.[online]. Ministerstvo vnútra SR [cit. 2012-01-20]. Available at: $<$ http://www. minv.sk/swift_data/source/policia/dopravna_policia/statistika_dn/Prehladl_DN.pdf $>$. (in Slovak).

ŠTETINA, Jaromír, at al. (2000). Disaster medicine and mass disasters. Praha: Grada Publishing, spol. s.r.o. 2000. 436 p. ISBN 80-7169-688-9. (in Czech). 